\title{
BLOOD LIPIDS OF THE SMALL OCTOPUS, OCTOPUS TEHUELCHUS (MOLLUSCA, CEPHALOPODA) AT DIFFERENT STAGES OF SEXUAL MATURATION
}

\author{
Horacio Heras and Ricardo J. Pollero* \\ Instituto de Investigaciones Bioquimicas de la Plata (UNLP-CONICET), Fac. de Cs. Mèdicas, \\ 60 y 120 , La Plata (1900), Argentina
}

\begin{abstract}
The lipid and fatty acid composition from the plasma and hemocytes in Octopus tehuelchus at different stages of sexual development, was determined.

2. The highest content of lipids was found in females engaged in egg development, and the lowest in post-spawning and brooding females. Highest levels occurred during the autumn season in both sexes.

3. Changes were mainly due to triacylglycerols and diacylglyceryl ethers.

4. The plasma fatty acid composition did not demonstrate significant changes at different stages of maturation. The arachidonic acid $(20: 4 \omega 6)$ was present at surprisingly high levels.
\end{abstract}

\section{INTRODUCTION}

The lipid fatty acid composition has been determined in tissues of several species of octopus (Thompson and Lee, 1965; Isay and Busarova, 1984; Koning, 1972). As part of a programme concerned with energy consumption during the female starvation period (Pollero and Iribarne, 1988) we have recently determined the lipid and fatty acid composition of the small species, Octopus tehuelchus. While there is information in the literature on blood circulating elements in octopus, this mainly refers to proteins (Salvato et al., 1979; Miller and Van Holde, 1982; van Bruggen et al., 1962), but there are no data in the literature concerning the detailed blood lipid composition.

The major goal of the present research was to determine the lipid and fatty acid composition of plasma and hematic cells in $O$. tehuelchus specimens with regard to different stages of sexual development. $O$. tehuelchus is a benthic species which dwells in shallow water in depths ranging from intertidal to $40 \mathrm{~m}$ in the San Matias Gulf, Patagonia, Argentina. During the spawning season, females lay eggs in empty mollusc shells; there follows a fasting period culminated by starvation. The mean weight of females decreases markedly during brooding (Iribarne, personal communication).

\section{MATERIALS AND METHODS}

\section{Sample collection}

The animals were collected by scuba diving in shallow sand bottom water $(<12 \mathrm{~m}$ deep) in the San Antonio Bay $\left(40^{\circ} 40^{\prime} \mathrm{S}-65^{\circ} 55^{\prime} \mathrm{W}\right)$, located on the north side of San Matias Gulf, Argentina. Thirty to forty specimens were captured in March, September and November. They were first examined to determine sex and sexual stages, and then classified as mature males with spermatophores in the penis, maturing

* Member of the Carrera del Investigador Cientifico, CIC Prov. de Buenos Aires, Argentina, and author to whom correspondence should be sent. females (I), mature females (II), and post spawning or brooding females (III) (Pujals, 1986). Blood from animals at each sexual stage was obtained by cardiac puncture. The blood samples were centrifuged at $2000 \mathrm{~g}$ for $15 \mathrm{~min}$ to separate hemocytes and plasma. The hemocyte-containing pellet was resuspended in distilled water. Samples were frozen and taken to the laboratory for analysis.

\section{Lipid extraction and analysis}

Total lipids were extracted with chloroform--methanol $(2: 1 \mathrm{v} / \mathrm{v})$ following the procedure of Folch et al. (1957). They were analysed by thin-layer chromatography (TLC) on plates of Silicagel $\mathrm{G}$ using hexane-ether-acetic acid $(80: 20: 2 \mathrm{v} / \mathrm{v})$ for neutral lipids, and chloroform-methanolacetic acid-water $(65: 25: 4: 4 \mathrm{v} / \mathrm{v})$ or chloroform-acetic acid-water $(50: 45: 5 \mathrm{v} / \mathrm{v})$ for phospholipids. Lipid classes were indentified as described previously (Pollero and Iribarne, 1988).

The quantitative determination of the lipid classes was performed by TLC coupled with a Flame Ionization Detector (FID) in a Iatroscan apparatus model TH-10, after separation on chromarods type $S$ using a triple development: hexane-benzene $(70: 30 \mathrm{v} / \mathrm{v})$ benzene-chloroformformic acid $(70: 25: 2 \mathrm{v} / \mathrm{v})$ and chloroform-methanol-water $(70: 25: 3 \mathrm{v} / \mathrm{v})$. The hydrogen pressure was fixed at $5 \mathrm{~kg} / \mathrm{cm}^{2}$ and air flow at $1200 \mathrm{ml} / \mathrm{min}$. Neutral and polar lipid classes were quantified by comparison with known amounts of standards run under the same conditions. Total lipids were calculated by summation of individual lipid weights.

\section{Fatty acid analysis}

Aliquots of extracts of total lipids were saponified with $10 \% \mathrm{KOH}$ in ethanol for $45 \mathrm{~min}$ at $80 \mathrm{C}$. The unsaponifiable fractions were extracted with petroleum ether and discarded. The fatty acids were extracted with petroleum ether and esterified with $3 \mathrm{~N} \mathrm{HCl}$ in methanol. Fatty acid methyl esters were analysed by gas-liquid chromatography (GLC) in a Hewlett-Packard 5840 apparatus equipped with a flame detector. A column packed with $10 \%$ sp-2330 on Chromosorb WAX was used. Temperature was programmed for a linear increase of $3^{\circ} \mathrm{C} / \mathrm{min}$ from 140 to $220^{\circ} \mathrm{C}$

The chromatographic peaks were tentatively identified after comparing their retention times with those of standards. The carbon chain length of the acids was checked by hydrogenation (Farquhar et al., 1959) and rechromato- 


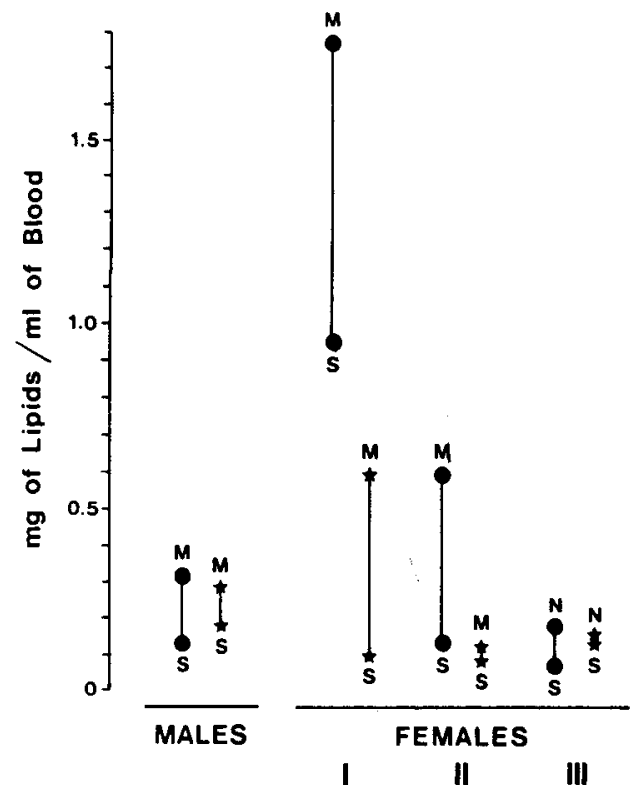

Fig. 1. Total lipids from plasma and hemocytes of $O$. tehuelchus at different sexual stages of development. O: Plasma; $\star$ : hemocytes; M: March; S: September; N: November

graphy of the staturated methyl esters. The number of double bonds was confirmed by the separation of methyl esters by TLC on Silicagel $\mathrm{H}-\mathrm{AgNO}_{3}$, followed by GLC of the separated fractions (Dudler and Anderson, 1975).

\section{RESULTS}

\section{Lipid composition}

Plasma and hemocyte total lipid content was determined in specimens of both sexes and females at different sexual stages. The results shown in Fig. 1 correspond to samples collected in March and September, except for brooding females which were captured in September and November (in March they are very scarce, and insufficiently advanced in their brooding stage). Both plasma and hematic cell lipids presented variations in accordance with sexual stage. Minor variations related to seasonal changes were also observed. When plasmatic total lipids were separated by TLC-FID using neutral lipid development solvents (see Materials and Methods), seven spots appeared. By comparison of their $\mathbf{R}_{f}$ values with those of authentic standards run under the same conditions and by colorimetric tests, they were identified as indicated in Table 1. Hydrocarbons, esterified sterols and wax esters were all quantified together since spots were not sharply separated. Variable amounts of triacylglycerols, depending on sexual maturation, were found. Cholesterol, depending on sexual stage and season, represented in some cases the major neutral lipid class. By using chloroform-methanol-water $(70: 25: 3 \mathrm{v} / \mathrm{v} / \mathrm{v})$ as developing solvents, polar lipids were resolved in three spots. These were mainly composed of phosphatidylcholine and phosphatidylethanolamine. Minor amounts of ceramide-aminoethylphosphonate (included in the phosphatidylcholine spot) and sphingomyelin were also identified.

The same lipid classes mentioned above were identified in the hematic cell extracts, though they occurred in different proportions to those in plasmatic extracts. The results summarized in Table 2 , show that cell lipids were mostly composed of phosphatidylcholine and cholesterol, the two components comprising from 54 to $90 \%$ of the total lipid content.

\section{Fatty acid composition}

The fatty acid composition of plasma samples from specimens at different sexual stages, is shown in Table 3. Twenty-two main fatty acid methyl ester peaks appeared in the GLC chromatograms. Saturated fatty acids of 14, 15, 16, 17, 18, 20 and 22 carbons were detected when the total fatty acids methyl esters were hydrogenated and rechromatographed. Fractionation of the fatty acid methyl esters by TLC- $\mathrm{AgNO}_{3}$, revealed the presence of saturated esters and unsaturated compounds of $1,2,3,4,5$ and 6 double bonds. Each fraction was analysed again by GLC to confirm the previously assigned identification. The results showed that the most abundant plasmatic fatty acids are: palmitic $(16: 0)$, stearic $(18: 0)$, arachidonic $(20: 4 \omega 6)$, eicosapentaenoic $(20: 5 \omega 3)$ and docosahexaenoic $(22: 6 \omega 3)$.

Table 1. Plasma lipid composition of $O$. teheulchus at different sexual stages $(\% \mathrm{w} / \mathrm{w})$

\begin{tabular}{|c|c|c|c|c|c|c|c|c|}
\hline \multirow{3}{*}{ Sexual stage } & \multirow{2}{*}{\multicolumn{2}{|c|}{ Males }} & \multicolumn{6}{|c|}{ Females } \\
\hline & & & \multicolumn{2}{|c|}{ I } & \multicolumn{2}{|c|}{ II } & \multicolumn{2}{|c|}{ III } \\
\hline & $\mathbf{M}$ & $\mathbf{S}$ & $\mathbf{M}$ & $\mathbf{S}$ & $\mathbf{M}$ & $\mathbf{S}$ & $\mathbf{N}$ & $\mathbf{S}$ \\
\hline $\left.\begin{array}{l}\text { Hydrocarbons } \\
\text { Esterified sterols } \\
\text { Wax esters }\end{array}\right\}$ & 16.5 & 12.6 & 29.3 & 11.1 & 66.7 & 8.8 & 2.9 & ND \\
\hline Diacylglycerylethers & 14.8 & 1.6 & 36.5 & 16.4 & 1.6 & 0.8 & ND & 4.4 \\
\hline Triacylglycerols & 16.0 & 1.7 & 23.4 & 42.2 & 2.0 & 2.3 & 7.5 & 3.5 \\
\hline Free fatty acids & 5.5 & 2.9 & 2.4 & 12.1 & 1.5 & 2.7 & 5.9 & 5.1 \\
\hline Cholesterol & 25.0 & 17.6 & 2.5 & 7.6 & 8.9 & 18.6 & 12.7 & 42.0 \\
\hline Total neutral lipids & 77.8 & 36.4 & 94.1 & 89.4 & 80.7 & 33.2 & 29.0 & 55.0 \\
\hline Phosphatidylethanolamine & 2.9 & 7.0 & 0.3 & 1.0 & 1.6 & 6.9 & 18.7 & 2.8 \\
\hline $\left.\begin{array}{l}\text { Ceramideaminoethyl phosphonate } \\
\text { Phosphatidylcholine }\end{array}\right\}$ & 19.3 & 54.4 & 5.4 & 9.6 & 17.1 & 57.7 & 51.2 & 41.6 \\
\hline Sphingomyelin & ND & 2.2 & 0.2 & ND & 0.6 & 2.2 & 1.1 & 0.6 \\
\hline Total polar lipids & 22.2 & 63.6 & 5.9 & 10.6 & 19.3 & 66.8 & 71.0 & 45.0 \\
\hline
\end{tabular}

Total plasmatic lipids were extracted from groups of 3-23 animals.

Lipid classes were identified by colour tests and quantified by TLC-FID.

ND: not detectable; M, S. and N: samples collected in March, September and November, respectively. 
Table 2. Lipid composition of hemocytes of $O$. teheulchus ( $\%$ w/w

\begin{tabular}{|c|c|c|c|c|c|c|c|c|}
\hline \multirow[b]{3}{*}{ Sexual stage } & \multirow{2}{*}{\multicolumn{2}{|c|}{ Males }} & \multicolumn{4}{|c|}{ Females } & \multirow{2}{*}{ ….. - } & \multirow[b]{3}{*}{$\mathbf{S}$} \\
\hline & & & \multicolumn{2}{|c|}{ I } & \multicolumn{2}{|c|}{ II } & & \\
\hline & $\mathbf{M}$ & $\mathbf{S}$ & $\mathbf{M}$ & $\mathbf{S}$ & $\mathbf{M}$ & $\mathbf{S}$ & $\mathbf{N}$ & \\
\hline $\left.\begin{array}{l}\text { Hydrocarbons } \\
\text { Esterified sterols } \\
\text { Wax esters }\end{array}\right\}$ & ND & ND & ND & ND & 1.6 & ND & 4.2 & 2.9 \\
\hline Diacylglycerylethers & ND & ND & ND & ND & ND & 1.2 & ND & 1.5 \\
\hline Triacylglycerols & $5 . \overline{3}$ & ND & 2.1 & ND & 5.2 & ND & 5.0 & ND \\
\hline Free fatty acids & 7.8 & 1.8 & 13.6 & 1.9 & 3.0 & 1.5 & 11.7 & 2.5 \\
\hline Cholesterol & 37.8 & 35.7 & 44.7 & 30.3 & 30.9 & 28.3 & 23.6 & 31.7 \\
\hline Total neutral lipids & 50.9 & 37.5 & 60.4 & 32.2 & 40.7 & 31.0 & 44.5 & 38.6 \\
\hline Phosphatidylethanolamine & 2.8 & 11.9 & 9.3 & 6.5 & 1.3 & 11.4 & 24.5 & 7.5 \\
\hline $\left.\begin{array}{l}\text { Ceramideaminoethyl phosphonate } \\
\text { Phosphatidylcholine }\end{array}\right\}$ & 46.3 & 48.7 & 24.6 & 60.3 & 47.4 & 55.8 & 31.0 & 51.9 \\
\hline Sphingomyelin & ND & 1.9 & 5.7 & 1.0 & 10.6 & 1.8 & ND & 2.0 \\
\hline Total polar lipids & 49.1 & 62.5 & 39.6 & 67.8 & 59.3 & 69.0 & 55.5 & 61.4 \\
\hline
\end{tabular}

See footnote to Table 1 .

\section{DISCUSSION}

The total lipid content of plasma samples reached a maximum in March and a minimum in September, respectively. Measurements carried out on plasma lipids during other seasons of the year demonstrated intermediate levels (results not shown). Since the highest values were found in March, and were independent of sex and sexual stage, they are ascribable to an increase in overall food intake during this season. Moreover, this is consistent with the weight increase of the specimens observed in this period (Iribarne, personal communication). The same trend, although more subtle, was also observed in the blood cell lipids. It can, therefore, be speculated that this finding indicates some role played by hemocytes in the lipid transport. Uptake and transport of certain lipid classes by hematic cells, has also been previously reported in other aquatic molluses following in vivo

Table 3. Plasmatic fatty acid composition of $O$. tehuelchus $(\% \mathrm{w} / \mathrm{w})$

\begin{tabular}{lrrrr}
\hline & & \multicolumn{3}{c}{ Females } \\
\cline { 4 - 5 } Fatty acids & Males & I & II & III \\
\hline $14: 0$ & 1.1 & 2.2 & 1.5 & 1.7 \\
$15: 0$ & 1.1 & 1.8 & 1.2 & 1.3 \\
$16: 0$ & 18.6 & 18.8 & 18.3 & 15.7 \\
$16: 1$ & 4.0 & 5.2 & 4.5 & 4.4 \\
$17: 0$ & 1.4 & 1.9 & 1.3 & 1.4 \\
$17: 1$ & 1.5 & 1.6 & 1.2 & 2.0 \\
$18: 0$ & 15.4 & 9.9 & 10.5 & 8.7 \\
$18: 1$ & 8.1 & 9.6 & 8.9 & 6.7 \\
$18: 2 \omega 6$ & 2.1 & 2.0 & 2.2 & 2.1 \\
$18: 3 \omega 6$ & $\mathrm{t}$ & 0.8 & $\mathrm{t}$ & 0.5 \\
$18: 3 \omega 3$ & 0.4 & 0.9 & 0.6 & 0.6 \\
$20: 1 \omega 9$ & 1.5 & 1.8 & 4.2 & 4.6 \\
$20: 2 \omega 6$ & 0.7 & 1.0 & 1.2 & 1.2 \\
$20: 3 \omega 6$ & 0.7 & 0.7 & 0.5 & $\mathrm{t}$ \\
$20: 4 \omega 6+22: 1^{*}$ & 9.4 & 10.4 & 10.8 & 11.1 \\
$20: 4 \omega 3$ & $\mathrm{t}$ & 1.0 & $\mathrm{t}$ & $\mathrm{t}$ \\
$20: 5 \omega 3$ & 8.6 & 15.6 & 12.4 & 10.9 \\
$22: 3 \omega 3$ & 3.9 & 1.5 & 1.2 & 2.2 \\
$22: 4 \omega 6$ & 3.6 & 0.9 & 3.6 & 4.4 \\
$22: 4 \omega 3$ & 2.7 & 0.3 & 1.9 & 3.1 \\
$22: 5 \omega 3$ & 4.4 & 2.5 & 4.3 & 5.3 \\
$22: 6 \omega 3$ & 10.8 & 9.6 & 9.7 & 12.1 \\
\hline
\end{tabular}

Fatty acid methyl esters were analysed by GLC in a SP-2330 column, before and after hydrogenation and $\mathrm{AgNO}_{3}-\mathrm{TLC}$ separation. Minor peaks are not included.

*22:1 acid represents a small quantity of the value. t: trace. and in vitro labelling experiments (Pollero et al., 1985; Pollero, 1987). However, the relative proportion of lipids in $O$. tehuelchus plasma and hemocytes, strongly indicates that most of the lipids are carried in association with plasma.

A previous study performed on $O$. tehuelchus demonstrated that female gonads contained higher levels of lipids than other tissues, and that this could be attributed to oogenesis since the gonadal lipid content increased in mature animals and decreased immediately after spawning (Pollero and Irebarne, 1988). Similar changes were also found in gonads of other aquatic invertebrates (Pollero et al., 1979, 1983). Thus, the noticeable enhancement of circulating lipids observed in $O$. tehuelchus females at stage I, might indicate a mobilization of nutritional material toward the gonads when the females are engaged in oocyte maturation. Both in mature and brooding females (stages II and III, respectively) the total lipids from plasma and hemocytes are comparatively low. Although lipids seem to play an important role in the gamete maturation, it has been demonstrated in $O$. teheulchus that they do not contribute as a main energy source during exercise or fasting. Under these conditions, the energy-providing role is mainly played by proteins and to a minor extent by glycogen (Pollero and Iribarne, 1988). These observations would explain the decrease of circulating lipids in mature and brooding females.

Neutral lipids, mainly triacylglycerols, diacylglyceryl ethers and some minor polar lipids, constitute the major total lipid fraction in the plasma of maturing females. The energy-providing role of triacylglycerols is well-known and has been widely established in other organisms. The amount of diacylglyceryl ethers is surprisingly high as compared to the low levels found in other $O$. tehuelchus tissues (Pollero and Iribarne, 1988). Although the energy function of diacylglyceryl ethers has not been proved beyond doubt, it is known that in bivalve molluses they decrease significantly during the starvation period (Pollero and Brenner, (1981). Thus the enhancement of both triacylglycerols and diacylglyceryl ethers in the plasma of maturing females may be consistent with the idea of a plasmatic supply of energy for oocyte development. The less polar fraction, composed of hydrocarbons, esterfied sterols and wax esters, represents in some cases an important 
lipid fraction, but their functions and seasonal fluctuations are not easily explained in the context of this research.

The principal difference between the lipids in hemocytes and in plasma is the predominance of phosphatidylcholine and free sterols in hemocytes.

? Phosphatidylcholine is particularly lamellophilic and it is an important component of cell membranes. Therefore, its accumulation in the hematic cells might $x$, be considered as an indicator of its functions in membrane organization. We have not attempted to identify all the sterols, but have considered only cholesterol since it comprises more than $90 \%$ of total sterol classes (results not shown). Since cholesterol is also a biological membrane constituent, its high concentration in hemocytes could be attributed to its accumulation in the cell membrane. However, another physiological role of hemocytes must be considered since even if fluctuations in the sterol proportions of membranes are possible, depending upon the tissue, the total sterol-phosphatydilcholine radio always remains less than one (Irazù et al., 1988). We found that in O. tehuelchus hemocytes, this ratio indicates changes dependent on seasonal and sexual stages, but it is inverted in mature females collected in March. This leads us to suggest that cholesterol is partly carried by hemocytes. This hypothesis is supported by a recent demonstration of cholesterol transport by hematic cells in bivalve molluscs (Pollero, 1987).

The qualitative composition of plasmatic fatty acids is the same as the one we initially found in tissue analyses of $O$. tehuelchus (results not published). No major changes in the quantitative fatty acid composition related to plasma transport at different stages of sexual maturation were found, either. The overall fatty acid spectrum corresponds to the general aquatic pattern, where the acids of linolenic series $(\omega 3)$ prevail over those of the linoleic series $(\omega 6)$. However, it is worth noticing that the proportion of saturated fatty acids, mainly represented by palmitic and stearic acids, is particularly high in all the stages. There is also a high arachidonic acid concentration in comparison with other marine molluscs including Octopoda (Issay and Busarova, 1984). Although this fatty acid is known to be abundant in freshwater invertebrates, it is usually present only in small amounts in marine species (no more than 4\%). However, the levels of arachidonated attained in $O$. tehuelchus are of the same order as those found in freshwater bivalves and crustaceans (Pollero et al., 1981; Gonzalez Barò and Pollero, 1988). This finding seems to be rather anomalous, and is at variance with all other data on cephalopods currently reported in the literature where the eicosapentenoic and docosahexaenoic acids are found to be the major polyunsaturated fatty acids in the tissues (Forneris et al., 1981; Josephs, 1982). A valid explanation for this high quantity of circulating arachidonic acid cannot be derived from the results obtained in the present study. However this unusual level might be related with the eicosanoid production or to some special requirement of membranes.

Further research will be necessary to learn in detail about the mode of lipid transport in cephalopods. To this end, we are studying the chemical and physical characteristics of some lipoproteic fractions isolated from $O$. tehuelchus.

Acknowledgements - This research has been supported by a grant from CONICET, Argentina. The authors are indebted to Mrs E. Bozzolo for her technical assistance and to the staff of Laboratorio de Recursos Bentonicos y Cultivos Marinos, Inst. de Biologia Marina y Pesquera "Alte Storni", Argentina, for their help.

\section{REFERENCES}

Dudley P. A. and Anderson R. E. (1975) Separation of polyunsaturated fatty acids by argentation thin layer chromatography. Lipids 10, 113-115.

Farquhar J. W., Insull W., Rosen P., Stoffel W. and Ahrens R. H. (1959) The analysis of fatty acid mixtures by gas-liquid chromatography. Nutrl. Rev. 17, Suppl. 8, 29-30.

Folch J., Lees M. and Sloane-Stanley G. H. (1957) A simple method for the isolation and purification of total lipids from animal tissues. J. biol. Chem. 226, 497-509.

Forneris S., Guidetti M. L. and Sarra C. (1981) Quantitative determination of eicosapentaenoic acid in some species of aquatic animals. Riv. Soc. Ital. Sci. Aliment. 10, 155-158.

Gonzalez Barò M. and Pollero R. J. (1989) Lipid characterization and distribution among tissues of the freshwater crustacean Macrobrachium borelii during an annual cycle. Comp. Biochem. Physiol. (in press).

Irazù C. E., Pollero R. J. and Brenner R. R. (1988) Fitosterol effect upon microsomal membrane microviscosity of Diplodon delodontus. Comp. Biochem. Physiol. 89B, 465470 .

Isay S. V. and Busarova N. G. (1984) Study on fatty acid composition of marine organisms-l. Unsaturated fatty acids of Japan Sea invertebrates. Comp. Biochem. Physiol. 77, 803-810

Josephs J. D. (1982) Lipid composition of marine and estuarine invertebrates. Part II: Mollusca. Prog. Lipid Res. 21, 109-153.

Koning A. J. (1972) phospholipids of marine origin VI. The octopus (Octopus vulgaris). J. Sci. Fd Agric. 23, 1471-1975.

Miller K. and Van Holde K. E. (1982) The structure of Octopus dofleini hemocyanin. Comp. Biochem. Physiol. 73B, $1013-1018$.

Pollero R. J., Re M. and Brenner R. R. (1979) Seasonal changes in the lipid of the mollusc Chlamys tehuelcha. Comp. Biochem. Physiol. 64A, 257-263.

Pollero R. J. (1987) Transport of cholesterol in the hemolymph of the mollusc Diplodon delodontus. Comp. Biochem. Physiol. 88A, 577-580.

Pollero R. J. and Brenner R. R. (1981) Effect of the environment and fasting on the lipid and fatty acid composition of Diplodon patagonicus. Lipids 16, 685-690.

Pollero R. J. and Iribarne O. (1988) Biochemical changes during the reproductive cycle of the small patagonian octopus, Octopus tehuelchus, D'Orb. Comp. Biochem. Physiol. 90B, 317-320.

Pollero R. J., Brenner R. R. and Gros E. G. (1981) Seasonal changes in lipid and fatty acid composition of the freshwater mollusk, Diplodon patagonicus. Lipids 16, 109-113.

Pollero R. J., Irazù C. E. and Brenner R. R. (1983) Effect of sexual stages on lipids and fatty acids of Diplodon delodontus. Comp. Biochem. Physiol. 76B, 927-931.

Pollero R. J., Huca G. and Brenner R. R. (1985) Role of hemocytes and plasma on lipid transport in the freshwater mollusc Diplodon delodontus. Comp. Biochem. Physiol. 82A, 339-343.

Pujals M. A. (1986) Contribuciòn al conocimiento de la biologia de Octopus tehuelchus D'Orbigny (Mollusca: Cephalopoda). An Soc. Cientifica Arg. 114, 29-73.

Salvato B., Ghiretti-Magaldi A. and Ghiretti F. (1979) Hemocyanin of Octopus vulgaris. The molecular weight of 
the minimal functional subunit in $3 \mathrm{M}$ Urea. Biochem. N. Y. 18, 2731-2736.

Thompson G. and Lee R. (1965) Studies of the $\alpha$-glyceryl ether lipids occurring in molluscan tissue. Biochim. Biophys. Acta 98, 151-159.
Van Bruggen E. F. J., Wiebenga E. H. and Gruber M. (1962) Structure and properties of hemocyanins II. Electron micrographs of the hemocyanins of Sepia officinalis, Octopus vulgaris and Cancer pagurus. J. molec. Biol. 4, 8-9. 